\title{
Rotational Spectra of Tetracyclic Quinolizidine Alkaloids: Does a Water Molecule Flip Sparteine?+
}

\author{
Alberto Lesarri, ${ }^{* a}$ Ruth Pinacho, ${ }^{\mathrm{b}}$ Lourdes Enríquez, ${ }^{\mathrm{b}}$ José E. Rubio, ${ }^{\mathrm{b}}$ Martín Jaraíz, ${ }^{\mathrm{b}}$ José \\ L. Abad, ${ }^{c}$ Marco A. Gigosos ${ }^{d}$
}

\footnotetext{
aDepartamento de Química Física y Química Inorgánica, Facultad de Ciencias, Universidad de Valladolid 47011 Valladolid (Spain), E-mail: lesarri@qf.uva.es, Homepage: http://www.uva.es/lesarri

${ }^{\mathrm{b}}$ Departamento de Electrónica, Escuela de Ingeniería de Telecomunicaciones, Universidad de Valladolid 47011 Valladolid (Spain)

'Spanish National Research Council (CSIC), Institute of Advanced Chemistry of Catalonia (IQAC-CSIC), Research Unit on Bioactive Molecules (RUBAM), Department of Biomedicinal Chemistry, 08034 Barcelona (Spain)

dDepartamento de Física Teórica, Atómica y Óptica, Facultad de Ciencias, Universidad de Valladolid 47011 Valladolid (Spain)

†Electronic supplementary information (ESI) available: Figures S1-S3, computational data (T ables S1-S3), experimental transitions (Tables S4-S6), rotational parameters for the ${ }^{18} \mathrm{O}$ water isotopologue (Table S7), atomic coordinates (Tables S8-S15) and binding energies (Tables S16). See DOI: xx.xxxx/xxxxxxxxxx.
} 
TOC Graphics

Rotational Spectra of Tetracyclic Quinolizidine Alkaloids: Does a Water Molecule Flip Sparteine?

A. Lesarri, ${ }^{*}$ R. Pinacho, L. Enríquez, J. E. Rubio, M. Jaraíz, J. L. Abad, M. A. Gigosos

Flipping or not flipping? The dimer of sparteine-water generated in a jet expansion retains the trans conformation of the parent molecule.

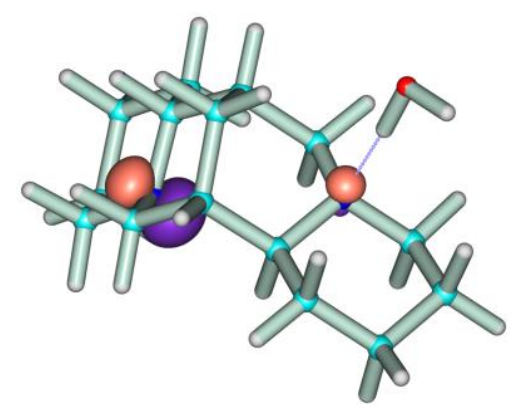




\begin{abstract}
Sparteine is a quinolizidine alkaloid used as chiral auxiliary in asymmetric synthesis. We examine whether hydration by a single molecule can flip sparteine from the most stable trans conformation to the bidentate cis arrangement observed in catalytic complexation to a metal center. Sparteine and the dimer sparteine-water were generated in a supersonic jet expansion with $\mathrm{H}_{2}{ }^{16} \mathrm{O}$ and $\mathrm{H}_{2}{ }^{18} \mathrm{O}$, and characterized by broadband chirped-pulse microwave spectroscopy. Despite the bidentate water dimer was predicted with larger binding energy, a single isomer was observed for the monohydrated cluster, with sparteine retaining the trans conformation observed for the free molecule. The absence of the bidentate dimer is attributed to kinetic control of the cluster formation, favoring the pre-expansion most abundant monomer. The structural properties of the $\mathrm{O}-\mathrm{H} \cdots \mathrm{N}$ hydrogen bond in the dimer are compared with complexes of other secondary and tertiary amines.
\end{abstract}




\section{Introduction}

The lupin alkaloid sparteine is a four-stereocenter tetracyclic chiral diamine belonging to the quinolizidine family.1 (-)-Sparteine (1, Scheme 1) occurs in all lupin species in various concentrations, while other less common diastereoisomers $(\mathbf{2}, \mathbf{3}, \mathbf{4})$ are naturally or synthetically available.2 The biosynthesis and pharmacological uses of quinolizidine alkaloids have been reviewed elsewhere.3'4 Sparteine has received widespread use in asymmetric synthesis, initially as chiral auxiliary with lithium and magnesium alkyls,5 and more recently with $4 \mathrm{~d}$ and $5 \mathrm{~d}$ transition metal systems. In particular, sparteine complexes with palladium are powerful catalysts with multiple applications including alcohol oxidations,6 direct Wacker oxidation,7 allylic alkylation8 and hydroalkoxylation of styrenes. 9

Structurally, sparteine is an apparently rigid tetracyclic made of two fused quinolizidine units, each consisting of two saturated six-membered rings with trans ring junctions (fusion by equatorial atoms). However, unlike rigid trans decalines, the two nitrogen atoms provide conformational flexibility trough ring inversion, resulting in several conceivable conformations. X-Ray diffraction and NMR have proved that upon chelation to a metal center sparteine adopts a $\eta_{2}$ bidentate configuration, 10 placing the two nitrogen lone pairs (lp) on the same molecular side to simultaneously point to the metal (cis-lp in Figure 1). However, theoretical calculations $11^{\prime} 12^{\prime} 13$ suggest that the bidentate configuration is not the most stable conformation for the bare molecule, predicting that the global minimum would exhibit trans nitrogen lone pairs (trans-lp) on opposing sides of the tetracyclic (as observed in crystal complexes with acetylenic alcohols14). In order to test these calculations and improve the structural information required for asymmetric induction models we have probed the conformational behaviour of the isolated molecule 
in a supersonic jet expansion, free of any solvent or matrix effects. Broadband fastpassage microwave spectroscopy was used to characterize the molecular properties through the structurally sensitive rotational spectrum. At the same time, and considering that a water molecule could act as proton donor simultaneously to both nitrogen lone pairs, we wondered whether a water molecule could flip the conformation of sparteine or not. Previous rotational data on microsolvated clusters rarely revealed conformational changes in the monomers, $15^{\prime} 16$ which however could be promoted here by the particular geometry of sparteine, favouring the formation of two simultaneous hydrogen bonds. This work is the first rotational study of a tetracyclic lupin alkaloid, as their relatively large molecular sizes have formerly restricted these studies except for the smaller bicyclic of lupinine.17 Solution studies by low-resolution $\mathrm{IR} / \mathrm{VCD}^{11}$ or $\mathrm{NMR}^{13}$ were interpreted in terms of a single trans-lp conformer.

\section{Experimental and Computational Methods}

The spectroscopic study used a commercial sample of (+)-sparteine (99\%, TCI), without further purification. The sample was vaporized in a heating reservoir located at the nozzle of a pulsed solenoid valve, at temperatures of $115^{\circ} \mathrm{C}$. The molecular jet was created by coexpansion of the sparteine vapors with a carrier gas (Ne, 1.8 bar) into an evacuated chamber (ca. $10^{-6}$ mbar). A nozzle diameter of $1.4 \mathrm{~mm}$ was used in all cases.

The jet was probed with a broadband chirped-pulse Fourier transform microwave (CP-FTMW) spectrometer, operating in the 2-8 GHz frequency range (BrightSpec Inc). The spectrometer operation follows a direct-digital fast-passage design by Pate 18 and Grabow.19 Briefly, short microwave chirps $(4 \mu \mathrm{s})$ covering a full frequency band are transmitted into the evacuated chamber to induce a macroscopic oscillating dipole 
moment in the supersonic jet, which propagates perpendicular to the exciting radiation. The rotational coherence decays are digitally recorded in the time domain, averaged and Fourier transformed to yield the resonance frequencies. Transition linewidths are narrower than $150 \mathrm{kHz}$. The accuracy of the frequency measurements is better than 3 $\mathrm{kHz}$.

The initial conformational search for sparteine and sparteine-water used molecular mechanics (MMFFs) and search algorithms based on stochastic and vibrational mode analysis.20 The MM geometries were reoptimized using ab initio (MP2) and densityfunctional-theory (M06-2X,21 B3LYP-GD322) molecular orbital calculations, yielding rotational constants and electrical properties. Computations were implemented in GAUSSIAN23 using a standard Pople triple- $\zeta$ 6-311++G(d,p) basis set. Vibrational frequency calculations predicted the harmonic force field and centrifugal distortion constants. For the monohydrated sparteine-water dimer the initial MM conformational search was followed by geometrical optimization with DFT theory and a reduced basis set $(\mathrm{M} 06-2 \mathrm{X} / 6-31+\mathrm{G}(\mathrm{d}, \mathrm{p}))$, in order to speed-up convergence. The most stable conformations were later reoptimized with the same methods and basis set used for sparteine. The calculation of binding energies for the dimers accounted for basis set superposition errors (BSSE) with the counterpoise approximation.24 The physical contributions to the binding potential of the water adducts were estimated by energy decomposition analysis using zeroth-order symmetry adapted perturbation theory ${ }^{24}{ }_{25}$ (SAPT), implemented in PSI4.26 


\section{Results and Discussion}

The final conformational energies for sparteine (Figure S1 and Table S1, ESI ${ }^{\dagger}$ ) consistently predict the trans-lp conformer (chair-chair-boat-chair A-B-C-D rings) as most stable, with the cis-lp structure (chair-chair-chair-chair) at relative energies between $8.9 \mathrm{~kJ} \mathrm{~mol}^{-1}$ (B3LYP-D3) and $15.3 \mathrm{~kJ} \mathrm{~mol}^{-1}$ (MP2). Five additional structures, including four conformations unnoticed in previous studies, ${ }^{11-13}$ were also calculated within an energy window of $42 \mathrm{~kJ} \mathrm{~mol}^{-1}$, but their relative energies $\left(>24 \mathrm{~kJ} \mathrm{~mol}^{-1}\right)$ preclude their observation in the gas phase. For the monohydrated sparteine-water dimer, the lowest lying $\left(<10 \mathrm{~kJ} \mathrm{~mol}^{-1}\right)$ water clusters combine the trans-lp or cis-lp conformations with hydration on one or two of the amine groups (Figures 2-3, Tables S2-S3, ESI ${ }^{\dagger}$ ). The higher energy dimers $\left(22-28 \mathrm{~kJ} \mathrm{~mol}^{-1}\right)$ exhibit hydration to the aliphatic skeleton.

The theoretical conformational stabilities were checked against the jet-cooled microwave spectrum in the $2-8 \mathrm{GHz}$ region. The initial spectral surveys contained only residual water from the inert carrier gas line, but still revealed two different sets of rotational transitions which were assigned independently. Both datasets comprised exclusively $R$-branch $(J+1 \leftarrow J) \mu_{\mathrm{a}}$-type transitions, with angular momentum quantum numbers spanning values of $J=5-15\left(\mu_{\mathrm{a}}\right.$ and $\mu_{\mathrm{c}}$ dipole moment components were consistently predicted ca. 3 times weaker). Nuclear quadrupole coupling hyperfine effects arising from the two ${ }^{14} \mathrm{~N}$ nuclei were not resolvable. The different rotational spectra suggested two carrier species, either from the monomer or its hydrates. Later addition of water to the gas line resulted in near depletion of the first species and enhancement of the second, confirming the detection of a water cluster. In order to assess the size of the hydrated molecule we added isotopically labeled ${ }^{18} \mathrm{O}$-water, which produced a new spectrum (Figure S2, Tables S4-S6, ESI ${ }^{\dagger}$ ). The experimental observations resulted in 
accurate rotational parameters for the three observed species, as reported in Tables 1-2, S7 $\left(\mathrm{ESI}^{\dagger}\right)$. No additional species were detectable in the spectrum.

The conformational assignment of sparteine was univocal on the basis of the large differences in rotational constants between the cis-lp and the trans-lp conformers. The experimental data in Table 1 undoubtedly confirm that the trans-lp conformer is the molecular global minimum. The agreement between the experiment and the three theoretical models is very good (relative deviations below 1\%), as expected for a relatively rigid structure (Tables S8-S9, ESI ${ }^{\dagger}$ ). The assignment of the sparteine-water dimer relied both on the rotational constants of the parent $\left(\mathrm{H}_{2}{ }^{16} \mathrm{O}\right)$ species and on the shifts of their values for the isotopically substituted $\mathrm{H}_{2}{ }^{18} \mathrm{O}$ isotopologue. A first comparison of the ${ }^{16} \mathrm{O}$-water rotational constants clearly suggests hydration of the translp isomer, with water attached to the amine group in the CD ring system. Differences in the treatment of dispersive forces in the MP2 and DFT methods are noticeable. The inclusion of empirical dispersion terms in B3LYP through the Grimme's D3 damping function $^{22}$ produces the best agreement in terms of the resulting structure $(<0.6-1.2 \%$, compared to $1.2-2.3 \%$ in M06-2X and $1.9-3.0 \%$ in MP2). Definitive support for this assignment is obtained from the ${ }^{18} \mathrm{O}$-water dimer data. The oxygen atom coordinates derived with the Kraitchman equations 27 are only compatible with hydration in the CD ring (Tables S10-S11, ESI ${ }^{\dagger}$ ). Hydration on the AB amine group or on the bidentate cis-1p conformation is definitively excluded (Tables S12-S13, ESI ${ }^{\dagger}$ ). An effective structure of sparteine-water fitting three bonding parameters $(r(\mathrm{O} \cdots \mathrm{N}), \angle(\mathrm{O} \cdots \mathrm{N}-\mathrm{C} 11)$ and $\tau(\mathrm{O} \cdots \mathrm{N}-$ C11-C12) satisfactorily reproduces the experimental rotational constants $(<0.2 \mathrm{MHz}$ for $B$ and $C,<6.5 \mathrm{MHz}$ for $A$, Figure S3, Table S14, ESI ${ }^{\dagger}$ ). The effective structure results in a relatively short and quasi-linear hydrogen bond $(r(\mathrm{O}-\mathrm{H} \cdots \mathrm{N})=1.778 \AA, \angle(\mathrm{O}-$ $\left.\mathrm{H} \cdots \mathrm{N})=171.2^{\circ}\right)$, slightly shorter than the theoretical prediction $(\mathrm{B} 3 \mathrm{LYP}-\mathrm{D} 3: r(\mathrm{O}-\mathrm{H} \cdots \mathrm{N})=$ 
$1.853 \AA$ ) and the observations in crystals of acetylenic alcohols $(1.80 \AA) .{ }^{14}$ Comparable predictions for sparteine-(water $)_{2}$ are in Table S15 (ESI $\left.{ }^{\dagger}\right)$.

The combination of jet-cooled rotational data and molecular orbital calculations has thus provided a conformational description of free sparteine and its monohydrated dimer. The experimental observation of trans-lp in the gas phase confirms this structure as the molecular global minimum, as predicted theoretically. The all-chair (CCCC) cis-lp conformation was not detected, as the relative energies of 8.9 (MP2) - 15.3 (B3LYP-D3) are consistent with their practical depopulation in the jet.

A single conformation was observed for the dimer sparteine-water, in which the trans-lp global minimum of sparteine is hydrated in rings CD. We did not observe hydration of the bidentate conformer cis-lp. However, there is no simple answer to the question whether a single water molecule can flip sparteine from the trans- to the cis-lp forms by formation of a double hydrogen bond to the two nitrogen lone pairs. The Gibbs energy ordering for the water cluster is not totally conclusive (Figure 3, Table 2). The M06-2X and MP2 methods predict the (trans-lp) - water (CD) dimer as most stable by 1.5-4.4 $\mathrm{kJ} \mathrm{mol}^{-1}$, while B3LYP-D3 produces very close relative energies $\left(<1 \mathrm{~kJ} \mathrm{~mol}^{-1}\right)$ and a reversed ordering favoring the bidentate dimer. On the other hand, the strength of the hydrogen bond in intermolecular complexes should be measured in terms of the binding energy instead of the electronic energies. The binding energies in Table 2 clearly predict a stronger hydrogen bond for the bidentate water complex for all three theoretical methods, with large differences of 10.4-13.9 $\mathrm{kJ} \mathrm{mol}^{-1}$ with respect to the trans-lp complexes. In this scenario, a water molecule can actually flip and stabilize a bidentate sparteine. The absence of the bidentate dimer must then be attributed to the characteristics of our supersonic jet experiment. While an adiabatic expansion generates transient intermolecular clusters at very low internal temperatures $\left(T_{\mathrm{rot}} \approx 2-5 \mathrm{~K}\right)$, the cluster 
formation is not controlled thermodynamically, but kinetically. The three-body collisions generating the adducts take place only in the vicinity of the nozzle, and the subsequent expansion freezes the initial dimers before they can thermalize. For this reason, the experimentally observed complex does not correspond to the most stable dimer species, but to the most abundant monomer trans-lp, preventing here the observation of the bidentate cis-lp adducts. This kinetic control has been observed in previous jet experiments with similar conclusions. 28

The mono-hydrated sparteine dimer provides interesting structural and energetic details on the $\mathrm{O}-\mathrm{H} \cdots \mathrm{N}\left(s p^{3}\right)$ hydrogen bond to cyclic amines. Alkylated amines are powerful hydrogen acceptors, as evidenced by the linearity, hydrogen bond distances and interaction energies of sparteine-water and other gas-phase hydrated dimers in Table S16 (B3LYP-D3). Substituent effects are evident in the hydrogen bond distances $\mathrm{r}(\mathrm{H} \cdots \mathrm{N})$ when passing from primary (aniline-water29: $1.995 \AA$ ) to secondary (piperidine-water30: $1.875 \AA$ A , pyrrolidine-water31: $1.877 \AA$, morpholine-water32: $1.881 \AA$ ) and tertiary amines (tropinone-water33: $1.845 \AA$, trimethylamine-water34: $1.868 \AA$ ), as addition of methyl groups renders the amino group more basic. The predicted binding energies follow a similar trend, with hydration to tertiary amines like tropinone $\left(-42.3 \mathrm{~kJ} \mathrm{~mol}^{-1}\right)$ and sparteine $\left(-43.4\right.$ to $\left.-54.1 \mathrm{~kJ} \mathrm{~mol}^{-1}\right)$ evidencing stronger hydrogen bonds compared to secondary (piperidine: $-41.6 \mathrm{~kJ} \mathrm{~mol}^{-1}$, pyrrolidine: $-41.3 \mathrm{~kJ} \mathrm{~mol}^{-1}$ ) or primary amines (aniline: $-27.3 \mathrm{~kJ} \mathrm{~mol}^{-1}$ ). For comparison, binding energies of water to the peptide group are lower than $-28 \mathrm{~kJ} \mathrm{~mol}^{-1}$ (B3LYP).35 In sparteine-water the formation of two hydrogen bonds in the bidentate isomer notably increases the interaction energy by more of $10 \mathrm{~kJ}$ mol $^{-1}$, justifying the use of this conformation in complexation to metal centers, as observed in solid state structures. A similar contraction in $\mathrm{O}-\mathrm{H} \cdots \mathrm{N}$ hydrogen bonds as well as increase in binding energies has been predicted for prototype complexes of amines 
and hydrogen halides. 36 A review of $\mathrm{O}-\mathrm{H} \cdots \mathrm{N}\left(s p^{2}\right)$ interactions in crystals found hydrogen bond distances in the range 1.83-2.02 $\AA .37$

A categorization of the physical forces stabilizing the sparteine-water dimer was obtained from SAPT energy partition analysis, 38 and compared with prototype dimers dominated by electrostatic (water39 and sevoflurane40 dimers), dispersive (pyridinemethane41) or mixed regimes (sevoflurane-benzene42). Sparteine-water exhibits a large and prevailing coulombic interaction, characterizing the $\mathrm{O}-\mathrm{H} \cdots \mathrm{N}$ interaction as a conventional electrostatically dominated hydrogen bond (Table 3).

\section{Conclusion}

In conclusion, the use of new fast-passage chirped-pulse broadband techniques in microwave spectroscopy is rapidly expanding the size and scope of molecular systems that can be examined with rotational resolution, as illustrated for tetracyclic sparteine and its monohydrated adduct. We characterized the $\mathrm{O}-\mathrm{H} \cdots \mathrm{N}$ hydrogen bond interaction and examined the influence of the monomer conformation on the structure and energetics of the monohydrated dimer. Despite the bidentate isomer could not be observed because of the large population differences for the monomer, we emphasize the importance of analyzing conformational changes on hydrogen bond complexation, scarcely observed in the gas-phase. Gas-phase studies of stereoselective effects in complexes of sparteine with more complex chiral molecules would now be feasible, offering empirical data for comparison with crystal diffraction experiments. Finally, the synergic approach contrasting high resolution rotational data with molecular orbital calculations proves a very effective test-bed for critical evaluation of $a b$ initio and density functional methods. 
This detailed description of intermolecular clusters may help to inform future molecular studies of chiral recognition and asymmetric synthesis.

\section{Acknowledgements}

Funding from MINECO-FEDER (CTQ2015-68148-C2-2-P) is gratefully acknowledged. 


\section{References}

1 (a) N. J. Leonard, The Alkaloids, Chemistry and Physiology, vol. III (Eds.: R. H. F. Manske and H. L. Holmes), Academic Press: New York, 1953. (b) T. Aniszewski, Alkaloids, Chemistry, Biology, Ecology

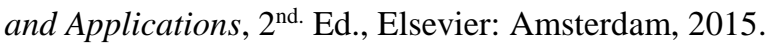

2 (a) N. J. Leonard, R. E. Beyler, J. Am. Chem. Soc., 1950, 72, 1316. (b) H. Oinuma, S. Dan, H. Kakisawa, J. Chem. Soc. Chem. Commun., 1983, 654.

3 (a) W. M. Golebiewski, I. D. Spenser Spenser, Can. J. Chem., 1988, 66, 1734. (b) J. Rana, D. J. Robins, J. Chem. Soc. Chem. Comm.,1983, 22, 1335.

4 M. Wink, T. Hartmann, Enzymology of Quinolizidine Alkaloid Biosynthesis, in Natural Products Chemistry (Eds.: R. I. Zalewski, J. J. Skolik), Elsevier: Amsterdam 1984.

5 (a) A. Beak, A. Basu, D. J. Gallagher, Y. S. Park, S. Thayumanavan, Acc. Chem. Res., 1996, 29, 552. (b) D. Hoppe, T. Hense, Angew. Chem. Int. Ed., 1997, 36, 2282. (c) A. R. Kennedy, C. T. O'Hara, Dalton Trans., 2008, 4975.

6 R. M. Trend, B. M. Stoltz, J. Am. Chem. Soc., 2008, 130, 15957.

7 C. N. Cornell, M. S. Sigman, Org. Lett., 2006, 8, 4117.

8 A. Togni, Tetrahedron: Assymmetry, 1991, 2, 683.

9 K. M. Gligorich, M. J. Schultz, M. S. Signman, J. Am. Chem. Soc., 2006, 128, 2794.

10 (a) R. Kuroda, S.F. Mason, J. Chem. Soc. Dalton Trans., 1977, 371. (b) H. Kageyama, K. Miki, Y. Kai, N. Kasai, Y. Okamoto, H. Yuki, Bull. Chem. Soc. Jpn., 1983, 56, 2411. (c) B. Jasiewicz, E. Sikorska, I. V. Khmelinskii, B. Warzajtis, U. Rychlewska, W. Boczon, M. Sikorski, J. Mol. Struct., 2004, 707, 89. (d) F. P. Intini, C. Pacifico, R. Z. Pellicani, V. Roca, G. Natile, Inorg. Chim. Acta, 2008, 361, 1606. (e) A. G. de Crisci, V. T. Anibale, G. K. Hamer, A. J. Lough, U. Fekl, Dalton Trans., 2010, 39, 2888.

11 P. Bour, J. McCann, H. Wieser, J. Phys. Chem. A, 1997, 101, 9783.

12 K. B. Wiberg, W. F. Bailey, J. Mol. Struct., 2000, 556, 239.

13 V. Galasso, F. Asaro, F. Berti, B. Kovac, I. Habus, A. Sacchetti, Chem. Phys., 2003, 294, 155.

14 F. Toda, K. Tanaka, H. Ueda, T. Oshima, J. Chem. Soc. Chem. Commun., 1983, 743.

15 W. Caminati, Microwave Spectroscopy of Large Molecules and Molecular Complexes, in Handbook of High Resolution Spectroscopy (Eds.: M. Quack and F. Merkt), Wiley: New York, 2011, pp. 829-852.

16 (a) M. J. Tubergen, C. R. Torok, R. J. Lavrich, J. Chem. Phys., 2003, 119, 8397. (b) A. R. Conrad, N.

H. Teumelsan, P. E. Wang, M. J. Tubergen, J. Phys. Chem. A, 2010, 114, 336.

17 M. K. Jahn, D. Dewald, M. Vallejo-López, E. J. Cocinero, A. Lesarri, J.-U. Grabow, J. Phys. Chem. A, 2013, 117, 13673.

18 a) C. Pérez, S. Lobsiger, N. A. Seifert, D. P. Zaleski, B. Temelso, G. C. Shields, Z. Kisiel, B. H. Pate, Chem. Phys. Lett., 2013, 571,1. b) J. L. Neill, S. T. Shipman, L. Alvarez-Valtierra, A. Lesarri, Z. Kisiel, B. H. Pate, J. Mol. Spectrosc., 2011, 269, 21. c) S. T. Shipman, B. H. Pate, New Techniques in Microwave 
Spectroscopy, in Handbook of High Resolution Spectroscopy (Eds.: M. Quack and F. Merkt), Wiley: New York, 2011, pp. 801-828.

19 J.-U. Grabow, Fourier Transform Microwave Spectroscopy Measurement and Instrumentation, in Handbook of High Resolution Spectroscopy (Eds.: M. Quack and F. Merkt), Wiley: New York, 2011, pp. 723-800.

20 (a) M. Saunders, K. N. Houk, Y.-D. Wu, W. C. Still, M. Lipton, G. Chang, W. C. Guida, J. Am. Chem. Soc., 1990, 112, 1419. (b) G. M. Keresu, I. Kolossváry, J. Am. Chem. Soc., 2001, 123, 12708

21 Y. Zhao, D. G. Truhlar, Theor. Chem. Acc., 2008, 120, 215.

22 S. Grimme, J. Antony, S. Ehrlich, H. Krieg, J. Chem. Phys., 2010, 132, 154104.

23 M. J. Frisch, G. W. Trucks, H. B. Schlegel, G. E. Scuseria, M. A. Robb, J. R. Cheeseman, G. Scalmani, V. Barone, B. Mennucci, G. A. Petersson, H. Nakatsuji, M. Caricato, X. Li, H. P. Hratchian, A. F. Izmaylov, J. Bloino, G. Zheng, J. L. Sonnenberg, M. Hada, M. Ehara, K. Toyota, R. Fukuda, J. Hasegawa, M. Ishida, T. Nakajima, Y. Honda, O. Kitao, H. Nakai, T. Vreven, J. A. Montgomery, Jr., J. E. Peralta, F. Ogliaro, M. Bearpark, J. J. Heyd, E. Brothers, K.N. Kudin, V. N. Staroverov, T. Keith, R. Kobayashi, J. Normand, K. Raghavachari, A. Rendell, J. C. Burant, S. S. Iyengar, J. Tomasi, M. Cossi, N. Rega, J. M. Millam, M. Klene, J. E. Knox, J. B. Cross, V. Bakken, C. Adamo, J. Jaramillo, R. Gomperts, R. E. Stratmann, O. Yazyev, A. J. Austin, R. Cammi, C. Pomelli, J. W. Ochterski, R. L. Martin, K. Morokuma, V.G. Zakrzewski, G. A. Voth, P. Salvador, J. J. Dannenberg, S. Dapprich, A. D. Daniels, O. Farkas, J. B. Foresman, J. V. Ortiz, J. Cioslowski, and D. J. Fox, Gaussian 09, Revision D.01, Gaussian, Inc., Wallingford CT, 2013.

24 S. Scheiner, Hydrogen Bond, A Theoretical Perspective, Oxford University Press: Oxford, 1997, and references therein.

25 B. Jeziorski, R. Moszynski and K. Szalewicz, Chem. Rev., 1994, 94, 1887.

26 J. M. Turney, A. C. Simmonett, R. M. Parrish, E. G. Hohenstein, F. A. Evangelista, J. T. Fermann, B. J. Mintz, L. A. Burns, J. J. Wilke, M. L. Abrams, N. J. Russ, M. L. Leininger, C. L. Janssen, E. T. Seidl, W. D. Allen, H. F. Schaefer, R. A. King, E. F. Valeev, C. D. Sherrill and T. D. Crawford, Wiley Interdiscip. Rev.: Comput. Mol. Sci., 2012, 2, 556.

27 H. D. Rudolph, J. Demaison in Equilibrium Molecular Structures (Ed.: J. Demaison, J. E. Boggs, A. G. Császar), Chap. 5, pp. 125-158, CRC Press: Boca Raton, FL, 2011.

28 a) C. Pérez, J. C. López, S. Blanco, M. Schnell, J. Phys. Chem. Lett., 2016, 7, 4053. b) W. Caminati, J. C. López, S. Blanco, S. Mata, J. L. Alonso, Phys. Chem. Chem. Phys., 2010, 12, 10230.

29 U. Spoerel, W. Stahl, J. Mol. Spectrosc., 1998, 190, 278.

30 U. Spoerel, W. Stahl, Chem. Phys., 1998, 239, 97.

31 W. Caminati, A. Dell'Erba, G. Maccaferri, P. G. Favero, J. Am. Chem. Soc., 1998, 120, 2616.

32 O. Indris, W. Stahl, U. Kretschmer, J. Mol. Spectrosc., 1998, 190, 372.

33 P. Écija, M. Vallejo-López, L. Evangelisti, J. A. Fernández, A. Lesarri, W. Caminati, E. J. Cocinero, ChemPhysChem, 2014, 15, 918.

34 M. J. Tubergen, R. L. Kuczkowski, J. Am. Chem. Soc., 1993, 115, 9263. 
35 P. Écija, F. J. Basterretxea, A. Lesarri, J. Millán, F. Castaño, E. J. Cocinero, J. Phys. Chem. A, 2012, 116, 10099.

36 Z. Latajka, S. Scheiner, H. Ratakczak, Chem. Phys., 1992, 166, 85.

37 A. L. Llamas-Saiz, C. Foces-Foces, O. Mo, M. Yañez, J. Elguero, Acta Crys. 1992, B48, 700.

38 S. Scheiner, Hydrogen Bond, A Theoretical Perspective, Oxford University Press: Oxford, 1997, and references therein.

39 T. R. Dyke, K. M. Mack, J. S. Muenter, J. Chem. Phys., 1977, 66, 498.

40 N. A. Seifert, C. Pérez, J. L. Neill, B. H. Pate, M. Vallejo-López, A. Lesarri, E. J. Cocinero, F. Castaño, Phys. Chem. Chem. Phys., 2015, 17, 18282.

41 Q. Gou, L. Spada, M. Vallejo-López, A. Lesarri, E. J. Cocinero, W. Caminati, Phys. Chem. Chem. Phys., 2014, 16, 13041.

42 N. A. Seifert, D. Zaleski, C. Pérez, J. L. Neill, B. H. Pate, M. Vallejo-López, A. Lesarri, E. J. Cocinero, F. Castaño, I. Kleiner, Angew. Chem. Int. Ed., 2014, 53, 3210. 
Scheme 1. Stereoisomers of sparteine.

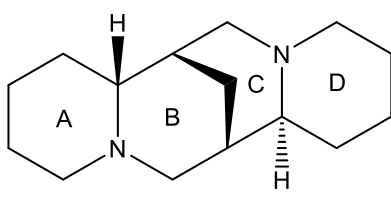

(-)-Sparteine (1) Lupinidine<smiles></smiles>

(-)- $\alpha$-Isosparteine (3)<smiles></smiles>

(-)- $\beta$-Isosparteine (4)<smiles>C[C@]12CCCCN1C[C@@H]1C[C@@H]2CN2CCCC[C@H]12</smiles>

(+)-Sparteine (2

Pachycarpine<smiles>C1CCN2C[C@H]3C[C@@H]([C@@H]2C1)[C@H]1CCCCN1C3</smiles>

$(+)-\alpha$-Isosparteine<smiles></smiles>

(+)- $\beta$-Isosparteine 
Figure 1. The HOMO orbital for the trans-lp and cis-lp conformers of sparteine (B3LYPD3/6-311++G(d,p)), showing the orientation of the lone pairs at the two nitrogen atoms.

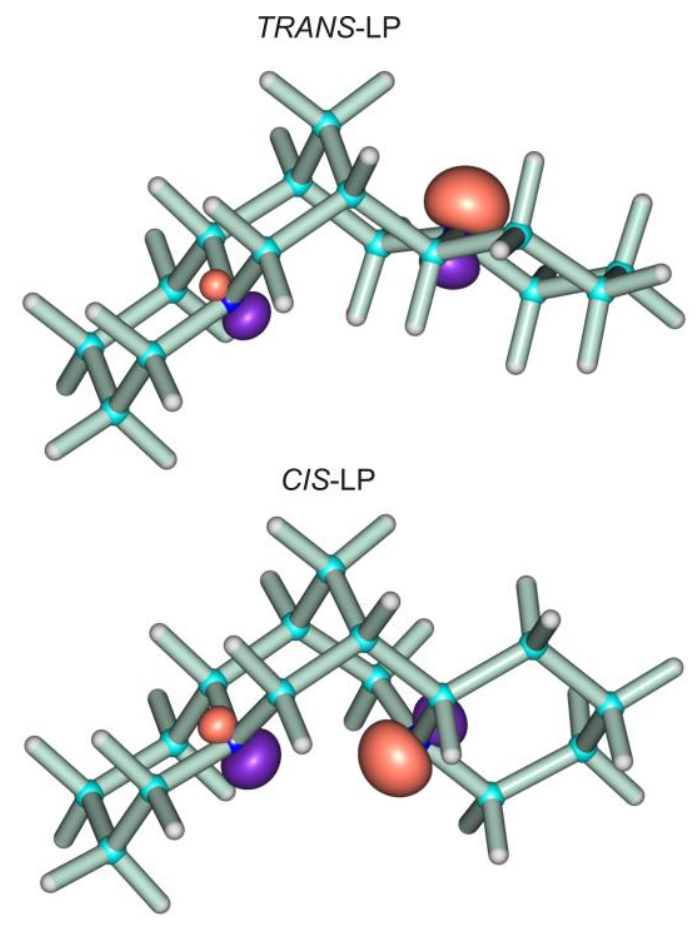


Figure 2. Relative Gibbs energies for the dimer sparteine-water using different ab initio and DFT methods. The four conformations with $\mathrm{O}-\mathrm{H} \cdots \mathrm{N}$ hydrogen bonds (blue panel) are more stable than water binding to the aliphatic skeleton (red panel). The lower panel shows an expansion for the most stable conformations.
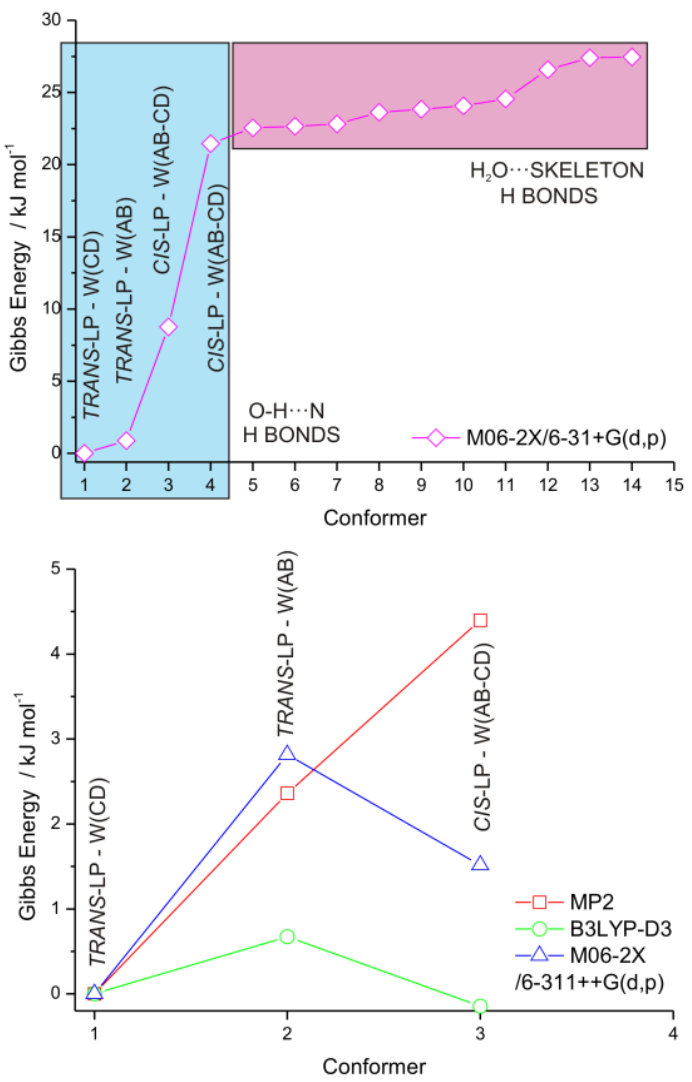
Figure 3. The three most stable isomers of the sparteine-water dimer combine trans-lp or cis-lp (bidentate) conformations with competing hydration on the $\mathrm{CD}, \mathrm{AB}$ or both $\mathrm{AB}-$ CD rings $(\mathrm{O}-\mathrm{H} \cdots \mathrm{N}$ hydrogen bonds distances in $\AA$ according to B3LYP-D3).
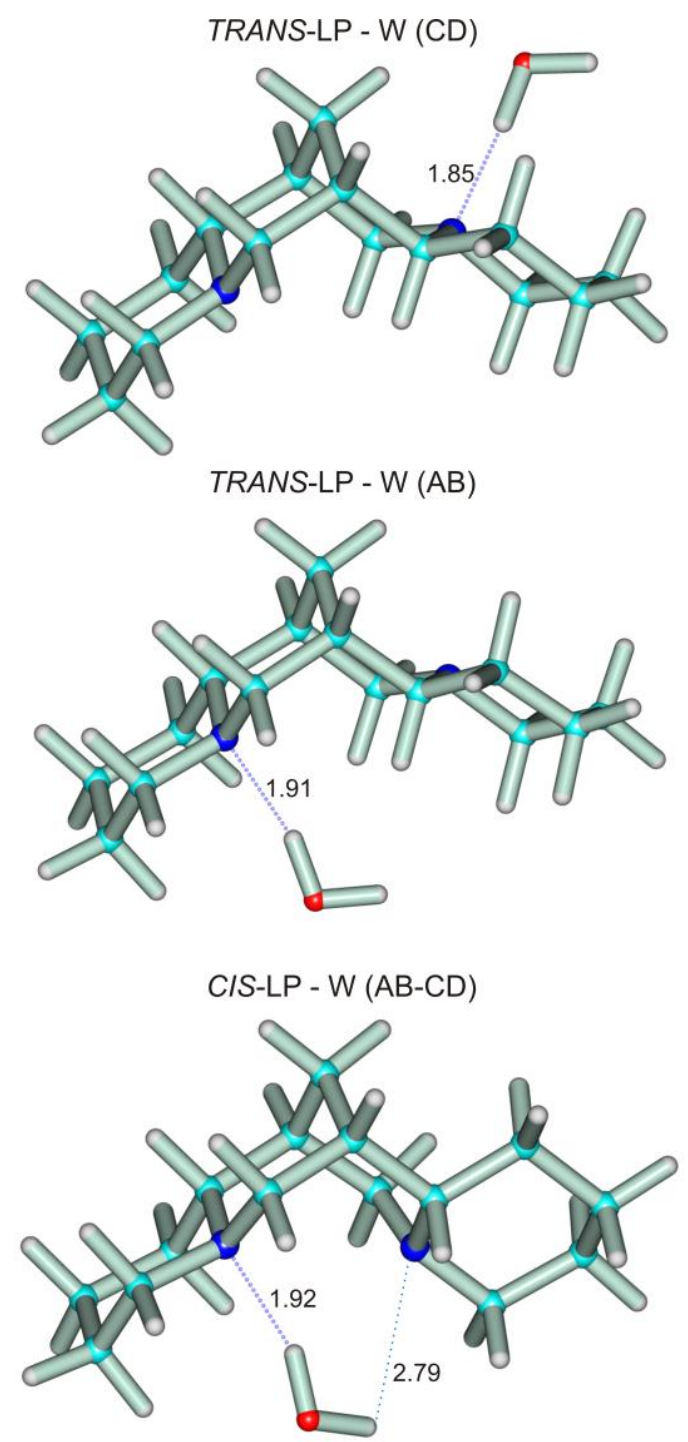
Table 1. Rotational parameters and model predictions for sparteine.

\begin{tabular}{cccc} 
& \multirow{2}{*}{ Experiment } & Theory $^{\mathrm{b}}$ & \\
\cline { 3 - 4 } & & Trans-lp & Cis-lp \\
\hline$A / \mathrm{MHz}$ & $980.20(14)^{\mathrm{c}}$ & $978.3 / 990.0 / 978.1$ & $958.6 / 958.3 / 955.7$ \\
$B / \mathrm{MHz}$ & $304.58447(51)$ & $307.1 / 304.8 / 302.0$ & $334.6 / 333.4 / 327.3$ \\
$C / \mathrm{MHz}$ & $290.35727(52)$ & $293.7 / 290.4 / 287.6$ & $311.7 / 310.7 / 306.1$ \\
$\Delta_{J} / \mathrm{Hz}$ & & $6.7 / 6.5 / 6.8$ & $9.4 / 9.9 / 8.2$ \\
$\Delta_{J K} / \mathrm{Hz}$ & $-53 . /-55 . /-59$. & $-59 . /-62 . /-51$. \\
$\Delta_{K} / \mathrm{kHz}$ & $0.20 / 0.21 / 0.23$ & $0.17 / 0.17 / 0.15$ \\
$\delta_{J} / \mathrm{Hz}$ & $-0.84 /-0.81 /-0.84$ & $1.2 / 1.2 / 0.92$ \\
$\delta_{K} / \mathrm{Hz}$ & $15 . / 15 . / 15$. & $-2.1 /-0.81 /-3.8$ \\
$\chi_{a a}\left({ }^{14} \mathrm{~N} 1\right) / \mathrm{MHz}$ & & $1.11 / 1.25 / 1.28$ & $0.67 / 0.72 / 0.71$ \\
$\chi_{b b}\left({ }^{14} \mathrm{~N} 1\right) / \mathrm{MHz}$ & & $2.47 / 2.71 / 2.84$ & $-1.53 /-1.60 /-1.77$ \\
$\chi_{c c}\left({ }^{14} \mathrm{~N} 1\right) / \mathrm{MHz}$ & & $-3.58 /-3.96 /-4.11$ & $0.86 / 0.88 / 1.06$ \\
$\chi_{a a}\left({ }^{14} \mathrm{~N} 2\right) / \mathrm{MHz}$ & & $0.31 / 0.45 / 0.43$ & $-3.43 /-3.6 /-3.58$ \\
$\chi_{b b}\left({ }^{14} \mathrm{~N} 2\right) / \mathrm{MHz}$ & & $1.03 / 1.03 / 1.11$ & $2.81 / 3.0 / 3.12$ \\
$\chi_{c c}\left({ }^{14} \mathrm{~N} 2\right) / \mathrm{MHz}$ & & $-1.33 /-1.48 /-1.54$ & $0.62 / 0.61 / 0.46$ \\
$\left|\mu_{a}\right| / \mathrm{D}$ & $0.67 / 0.65 / 0.56$ & $0.50 / 0.43 / 0.41$ \\
$\left|\mu_{b}\right| / \mathrm{D}$ & $0.22 / 0.23 / 0.17$ & $0.24 / 0.29 / 0.21$ \\
$\left|\mu_{c}\right| / \mathrm{D}$ & & $0.23 / 0.17 / 0.13$ & $0.46 / 0.48 / 0.44$ \\
$\mu_{T O T} / \mathrm{D}$ & & $0.75 / 0.71 / 0.60$ & $0.72 / 0.71 / 0.64$ \\
$\Delta E_{Z P E} / \mathrm{kJ} \mathrm{mol}{ }^{-1}$ & & $0.0 / 0.0 / 0.0$ & $15.4 / 13.1 / 8.9$ \\
$\Delta G / \mathrm{kJ} \mathrm{mol}{ }^{-1}$ & & $0.0 / 0.0 / 0.0$ & $15.3 / 12.6 / 8.9$ \\
$N$ & 57 & & \\
$\sigma / \mathrm{kHz}$ & 12.7 & & \\
\hline
\end{tabular}

a Rotational constants $(A, B, C)$, centrifugal distortion constants $\left(\Delta_{\mathrm{J}}, \Delta_{\mathrm{JK}}, \Delta_{\mathrm{K}}, \delta_{\mathrm{J}}, \delta_{\mathrm{K}}\right)$ in Watson's Areduced Hamiltonian ( $I^{r}$ representation), nuclear quadrupole coupling constants $(\chi \alpha \beta, \alpha, \beta=a, b, c)$, Electric dipole moments ( $\left.\mu_{\alpha}, \alpha=a, b, c\right)$, relative energies (including zero-point energies: $\Delta E_{Z P E}$ ), Gibbs free energies $(\Delta G: 298 \mathrm{~K}, 1 \mathrm{~atm})$, number of fitted transitions $(N)$ and rms deviation of the fit $(\sigma) .{ }^{b} \mathrm{MP} 2 / \mathrm{M} 06-2 \mathrm{X} / \mathrm{B} 3 \mathrm{LYP}-\mathrm{GD} 3$ calculations, respectively. 
Table 2. Rotational parameters and model predictions for the monohydrated dimer sparteine- $\mathrm{H}_{2}{ }^{16} \mathrm{O}$.

$$
\text { Experiment }
$$

Theory $^{b}$

Trans-lp-W(CD) Trans-lp-W(AB) Cis-lp-W(AB-CD)

\begin{tabular}{ccccc}
\hline$A / \mathrm{MHz}$ & $767.363(41)$ & $745.7 / 754.7 / 758.0$ & $772.7 / 780.2 / 782.0$ & $763.3 / 759.8 / 768.1$ \\
$B / \mathrm{MHz}$ & $268.12401(32)$ & $276.4 / 274.5 / 269.8$ & $286.1 / 286.2 / 282.0$ & $311.5 / 314.1 / 306.4$ \\
$C / \mathrm{MHz}$ & $251.39438(33)$ & $256.3 / 254.4 / 253.2$ & $276.8 / 278.4 / 275.5$ & $295.2 / 298.2 / 288.5$ \\
$\Delta_{J} / \mathrm{Hz}$ & $13.31(64)$ & $5.2 / 6.0 / 4.7$ & $5.3 / 4.6 / 4.7$ & $6.7 / 6.2 / 6.4$ \\
$\Delta_{J K} / \mathrm{Hz}$ & $-96.1(30)$ & $-13 . /-16 . /-14$ & $-6.9 /-7.5 /-8.4$ & $-14 . /-12 . /-19$. \\
$\Delta_{K} / \mathrm{kHz}$ & & $0.11 / 0.15 / 0.10$ & $0.068 / 0.056 / 0.064$ & $0.056 / 0.044 / 0.068$ \\
$\delta_{J} / \mathrm{Hz}$ & & $0.47 / 0.87 / 0.31$ & $0.52 / 0.56 / 0.57$ & $-0.082 /-0.068 / 0.038$ \\
$\delta_{K} / \mathrm{Hz}$ & & $15 . / 35 . / 24$. & $-70 . /-90 . /-10$. & $18 . / 21 . / 13$. \\
$\chi_{a a}\left({ }^{14} \mathrm{~N} 1\right) / \mathrm{MHz}$ & & $0.19 / 0.30 / 0.19$ & $1.01 / 1.07 / 1.06$ & $-3.37 /-3.63 /-3.57$ \\
$\chi_{b b}\left({ }^{14} \mathrm{~N} 1\right) / \mathrm{MHz}$ & & $-0.12 / 0.12 /-0.21$ & $-3.51 /-3.73 /-3.6$ & $1.24 / 1.31 / 1.52$ \\
$\chi_{c c}\left({ }^{14} \mathrm{~N} 1\right) / \mathrm{MHz}$ & & $-0.08 /-0.42 / 0.01$ & $2.49 / 2.67 / 2.61$ & $2.13 / 2.31 / 2.05$ \\
$\chi_{a a}\left({ }^{14} \mathrm{~N} 2\right) / \mathrm{MHz}$ & & $0.55 / 0.65 / 0.71$ & $0.71 / 0.71 / 0.79$ & $0.92 / 0.80 / 1.05$ \\
$\chi_{b b}\left({ }^{14} \mathrm{~N} 2\right) / \mathrm{MHz}$ & & $2.26 / 2.55 / 2.51$ & $-0.84 /-2.07 /-2.60$ & $-3.36 /-3.40 /-3.83$ \\
$\chi_{c c}\left({ }^{14} \mathrm{~N} 2\right) / \mathrm{MHz}$ & & $-2.81 /-3.2 /-3.2$ & $0.13 / 1.36 / 1.80$ & $2.44 / 2.60 / 2.78$ \\
$\left|\mu_{a}\right| / \mathrm{D}$ & & $0.55 / 0.55 / 0.66$ & $0.31 / 0.52 / 0.49$ & $1.53 / 1.41 / 1.66$ \\
$\left|\mu_{b}\right| / \mathrm{D}$ & & $2.43 / 2.53 / 2.43$ & $1.96 / 2.03 / 2.18$ & $2.17 / 1.96 / 2.31$ \\
$\left|\mu_{c}\right| / \mathrm{D}$ & & $0.96 / 0.56 / 1.03$ & $0.03 / 0.11 / 0.10$ & $1.68 / 1.72 / 1.56$ \\
$\mu_{T O T} / \mathrm{D}$ & & $2.67 / 2.64 / 2.73$ & $1.98 / 2.10 / 2.24$ & $3.14 / 2.97 / 3.24$ \\
$\Delta E_{Z P E} / \mathrm{kJ} \mathrm{mol}{ }^{-1}$ & & $0.0 / 0.0 / 2.4$ & $1.6 / 0.0 / 1.9 /$ & $2.0 /-2.2 / 0.0$ \\
$\Delta G / \mathrm{kJ} \mathrm{mol}{ }^{-1}$ & & $0.0 / 0.0 / 0.1$ & $2.4 / 2.8 / 0.8 /$ & $4.4 / 1.5 / 0.0$ \\
$E_{B} / \mathrm{kJ} \mathrm{mol}{ }^{-1}$ & & $-30.8 /-39.8 /-43.4$ & $-27.4 /-41.1 /-43.1$ & $-41.2 /-55.0 /-54.1$ \\
$N$ & & & & \\
$\sigma / \mathrm{kHz}$ & & & & \\
\hline
\end{tabular}

${ }^{a}$ Parameter definition as in Table 1, with addition of binding energies $E_{B}$ (BSSE corrected). ${ }^{\mathrm{b}} \mathrm{MP} 2 / \mathrm{M} 06-2 \mathrm{X} /$ B3LYP-GD3 predictions, respectively. 
Table 3. Binding energy decomposition for the dimer sparteine-water (SAPT(0)/jun-ccpVDZ, $\mathrm{kJ} \mathrm{mol}^{-1}$ ), and comparison with dimers dominated by electrostatic (water and sevoflurane dimers), dispersion (pyridine-methane) or intermediate (sevofluranebenzene) intermolecular interactions. The interaction energy is decomposed into electrostatic $\left(\Delta E_{\text {elec }}\right)$, inductive (multipole interactions/charge transfer, $\Delta E_{\text {ind }}$ ), exchange repulsion $\left(\Delta E_{\text {exch }}\right)$ and dispersion $\left(\Delta E_{\text {disp }}\right)$ energy terms.

\begin{tabular}{|c|c|c|c|c|c|}
\hline Cluster & $\Delta E_{\text {elect }}$ & $\Delta E_{\text {ind }}$ & $\Delta E_{\text {exch }}$ & $\Delta E_{\text {disp }}$ & $\Delta E_{\text {total }}$ \\
\hline Sparteine-water $(\text { cis-lp) })^{\mathrm{a}}$ & -75.5 & -25.5 & 81.5 & -28.8 & -48.3 \\
\hline Sparteine-water $(\text { trans-lp) })^{\mathrm{a}}$ & -71.2 & -27.2 & 84.6 & -24.0 & -37.8 \\
\hline$(\text { Water })_{2}{ }^{\mathrm{b}}$ & -37.0 & -9.0 & 29.4 & -5.3 & -21.8 \\
\hline (Sevoflurane) $)_{2}{ }^{\mathrm{c}}$ & -31.5 & -7.5 & 37.5 & -23.8 & -25.4 \\
\hline Sevoflurane-benzene $^{d}$ & -36.9 & -10.5 & 59.4 & -37.0 & -25.0 \\
\hline Pyridine-methane $\mathrm{e}^{\mathrm{e}}$ & -17.9 & -4.1 & 46.1 & -42.0 & -17.8 \\
\hline
\end{tabular}

